\title{
Matemática e problemas do cotidiano: estratégias para o ensino
}

\author{
Geraldina Porto Witter ${ }^{1}$ - Universidade Castelo Branco, São Paulo, Brasil
}

Immergut, B. (2010). Master math solving word problems. Boston, M.A.: Course Technology/Language Learning, ix + $178 \mathrm{p}$.

Parece haver um consenso em que, para se obter um bom resultado no ensino de Matemática é necessário que o professor tenha competência para estabelecer relações entre o assunto que está trabalhando e o mundo ou contexto de vida de seus alunos. Para atender a essa exigência como suporte para excelência no ensino é que o livro aqui resenhado foi elaborado.

Brita Immergut tem muitos anos de experiência em escolas de vários níveis, incluindo ser professora de matemática, física e química (Suécia) e ter doutorado em educação matemática pela Columbia University. Reúne no livro propostas de como trabalhar para vários temas, sendo muito clara e didática em suas exposições. É autora de outros livros e artigos sobre o ensino nessas áreas.

Suas propostas levam em consideração que nas histórias de aprendizagem muitas pessoas aprenderam a achar que os problemas são difíceis, tendo dificuldades para distinguir a verdadeira questão ou em não saber por onde começar. Vale dizer que aprenderam a temer ou a não aprender matemática. Assim, o livro apresenta uma série de estratégias e de problemas práticos para os professores eliminarem os referidos desvios.

Como o leitor-professor vai ter que lidar com equações necessárias para resolver a grande maioria dos problemas, a autora sugere a leitura do ApêndiceRevisão de Equações como ponto de início para os com dificuldades ou que queiram recordar a matéria de forma rápida e agradável. Leva em consideração que nem todos os professores dominam o necessário e suficiente da matéria, o que provavelmente também ocorre na realidade brasileira.

Nos vários capítulos há uma preocupação com a leitura do enunciado, a busca das palavras que permitam dividir o problema em segmentos que facilitam a solução e também em todos há preocupação com que os problemas sejam situações de vida diária. São de grande utilidade para professores de vários níveis, sugerindo exercícios nessa linha e

\footnotetext{
1 Endereço para correspondência:

Av. Pedroso de Moraes, 144 - Apto. 302 - Pinheiros 05420-000 - São Paulo-SP

E-mail: witter@uol.com.br
}

apresentando outros. Os problemas usados como exemplo são resolvidos no corpo do capítulo e as sugestões de problemas práticos têm sua solução no final do livro. A estrutura de cada capítulo compreende um enquadramento do tema e vários tipos de problemas relacionados com a vida diária, apresenta exemplos resolvidos (por equação e usando aritmética) e problemas práticos do cotidiano das pessoas.

O livro é constituído por oito capítulos com amplitudes variadas, enfocando problemas sobre os temas: equações simples, porcentagem, idade, mistos, mensuração, ritmo/velocidade, estatística, probabilidade e geometria.

A maior parte de cada capítulo é composta por propostas de problemas da realidade, de por onde começar e como resolvê-los, quer recorrendo aos conhecimentos de equações, quer usando a matemática. Nessas circunstâncias optou-se por destacar apenas alguns aspectos de alguns capítulos como ilustração.

No capítulo sobre equações simples há tópicos em que mostra como tomar decisões sobre a busca de soluções quando o enunciado inclui palavras como mais que e menos que. As pessoas tendem a pensar que a primeira expressão corresponde a adicionar e a segunda a subtrair, mas isso nem sempre é o caso. Demonstra com exemplos quando a operação é de um ou outro tipo, alertando para a estrutura discursiva. Seguem muitos exemplos da vida diária em que estas expressões aparecem e induzem o aluno ao erro. Também alerta para o uso < é menor que, que também pode ser entendido próximo de, $\leq$ é menor ou igual $\mathrm{a},>$ é maior que e $\geq$ é igual ou maior que, também passível de ser lido como pelo menos igual. É pelo enunciado ou outra pista verbal que se pode decidir com precisão, ao ler o problema, sobre como agir.

O capítulo 3 apresenta problemas avançados envolvendo idade, tempo, que muitas vezes requerem o uso de duas equações para que possam ser adequadamente resolvidos.

Para dar ao leitor uma perspectiva dos problemas tratados em cada capítulo optou-se por apresentar de um deles os itens enfocados. Assim, o Capítulo 5 tem por título Problemas de mensuração e está assim organizado: Razão e proporção, Proporção, 
mensuração e conversões, Sistemas de mensuração, Conversão entre sistemas, Análise dimensional e temperatura.

É um livro voltado para a prática educacional com exercícios para aprendizagem e para avaliação do aprendido. É muito útil a professores, psicólogos escolares, pedagogos e pesquisadores de educação matemática e a educadores de um modo geral.
Também é útil para os que se ocupam em resolver as condições de ensino para viabilizar a motivação e a aprendizagem eficiente de matemática.

Recebido em fevereiro de 2010 Aprovado em abril de 2010

Sobre a autora:

Geraldina Porto Witter é psicóloga, doutora em Ciências (USP), livre-docente em Psicologia Escolar (USP), professora emérita pela UFPb e pelo UNIPÊ. Atualmente coordena a implantação da Pós-Graduação, "Stricto Sensu", na Universdidade Castelo Branco - UNICASTELO. 